\title{
THE NETWORK STRUCTURE BETWEEN ORGANIZATIONS AND THE OPERATIONAL EFFICIENCY OF DRUG DEVELOPMENT
}

\author{
FUMIHIKO ISADA, YURIKO ISADA
}

\begin{abstract}
:
The sharp rise in health-care costs is compressing the public finance in various countries today, and an increase in the efficiency of the research and development of pharmaceutical products is required. In order to increase the efficiency of drug development, open innovation through external cooperation between drug manufacturing companies is attracting attention. However, the research findings of previous researches are not necessarily the same regarding the size of the effect of external cooperation between drug manufacturing companies. It is assumed that differences in the kinds of pharmaceutical products and in the mode of inter-organisational relations are two of the causes of the variation in the research findings. For example, with regard to the interorganisational relation mode, the operational efficiency of a horizontal international specialization style is high in the IT industry, and the operational efficiency of a vertical integration style is high in the motor industry. Thus, in this research, pharmaceutical products were classified appropriately and the inter-organisational relation fit for each was clarified empirically. As a method of research, from the intellectual-property database, the joint-application patents for the past ten years were extracted, and the inter-organisational relation was analysed by using the method of social network analysis. As a result, when the pharmaceutical products were classified using the conventional polymer formulation, the bio-drug development and the dosage-form development, the effect of external cooperation changed with differences in product characteristics. In addition, it became clear that the modes of external cooperation fit for each difference.
\end{abstract}

\section{Keywords:}

interorganisational relation, social network analysis, joint-application patent, pharmaceutical product, research and development.

JEL Classification: 032

\section{Authors:}

FUMIHIKO ISADA, The Faculty of Informatics, Kansai University, Japan, Email: isada@kansai-u.ac.jp YURIKO ISADA, School of Policy Studies, Kwansei Gakuin University, Japan, Email: yuriko@kwansei.ac.jp

\section{Citation:}

FUMIHIKO ISADA, YURIKO ISADA (2018). The Network Structure between Organizations and the Operational Efficiency of Drug Development. International Journal of Business and Management, Vol. 
VI(1), pp. 8-25., 10.20472/BM.2018.6.1.002 


\section{Introduction}

The objective of this research is to analyse the relationship between the network structure between organizations in the development of a drug and operational efficiency. As a precedent research to this research, a preliminary analysis of drug manufacturing companies in Japan was conducted by Isada \& Isada (2015). This research, as the succeeding research, classified the pharmaceutical products according to the type of product based on the patent application, and performed a comparative study. The background to the research is as follows.

The sharp rise in health-care costs is compressing the public finance in various countries today, and an increase in the efficiency of the research and development of pharmaceutical products is required. In the pharmaceutical industry, the research and development (R\&D) model, hitherto based on the economies of scale associated with conventional large-scale corporations, is changing. It is difficult for a large-scale corporation to raise revenue using the vertical integration style of business model based on insourcing products within a company using large-scale internal R\&D resources. The sizable technical transformation of biomedicines started with conventional low-molecule pharmaceutical products. It has become considerably more difficult to create large-sized blockbusters. Since the process for clinical trials has been tightened, the probability of success in launching a new drug is falling and the lead time to launch is becoming longer. Pharmaceutical companies always have to invest in pipelines with the advent of a new drug to sustain the vast corporate entity. For this reason, pharmaceutical companies are increasingly depending on external companies for the very uncertain R\&D of a new drug. The risk can be reduced by buying a potential new drug for which the R\&D process has been completed to some extent. The role of open innovation (Chesbrough, 2003) is thought to be important in such a transformation.

On the other hand, if the interorganisational relation between an existing enterprise and a venture business is observed, an interesting difference exists among different industries. In the IT industry, start-ups in Silicon Valley have repeatedly achieved considerable success. These ventures and others have greatly contributed to the promotion of innovation in the IT industry and the industry model has developed. In the IT industry, the open-network type of many-to-many cooperation has been a prime mover in the industry's development through the adoption of a horizontal specialization style, whereby various companies share a value chain and cooperate. However, in the relationship between organizations in the pharmaceutical industry, there are not many venture businesses that grow significantly as in the IT industry segment.

In contrast, in the motor vehicle industry, enterprise groups that have adopted a vertical integration model have now gained strong competitiveness. For some motor cars (e.g. electric vehicles), the activity of venture businesses adopting a horizontal specialization style has also attracted attention. Strongly competitive company groups have adopted 
the vertical integration model with a huge finished car maker at the summit of the pyramid. Interorganisational relationships are similar, not only in developed countries, such as in Europe, the United States (US) and Japan, but also in companies in emerging countries, such as South Korea, China and India. It seems that the model of close interorganisational relationships between individual firms fits the motor industry. Therefore, it is considered that there is a strong relationship between business competitiveness and interorganisational relationships. Moreover, it is thought that a desirable relationship changes with the industry, product characteristics and so on. It is important to consider what kind of relationship best suits each industry and product. Thus, the empirical study described in this paper aimed to examine what kind of interorganisational relationships are best suited to the pharmaceutical industry.

Furthermore, the optimal interorganisational relation may differ even within the pharmaceutical industry according to the type of product. The design of the development process differs between the conventional low-molecular-weight pharmaceutical products and the biomedicine of recent years. In addition, pharmaceutical manufacturers are researching and developing various dosage forms corresponding to the various needs of a medical institution or a patient. Since researchand-development processes differ between a drug development and a dosage form development, the optimal interorganisational relation may also differ.

As a method of determining the relationship between organizations, social network analysis was used in this research. As the object of research, data considered to be the result of open innovation were extracted from a database concerning intellectual property. From these data, various indicators were generated through network analysis showing the traits of relationships between organizations. Furthermore, the causeeffect relationship between each indicator and the productivity of R\&D were verified.

\section{Precedent research}

\subsection{Interpersonal ties}

Granovetter's (1973) paper on the strength of weak ties was a seminal work in the study of social networks and is an extremely famous publication in sociology more generally. According to Granovetter (2005), interpersonal ties generally come in three varieties: strong, weak or absent. Weak social ties, it is argued, are responsible for the majority of the embeddedness and structure of social networks in society, as well as the transmission of information through these networks. Specifically, more novel information flows to individuals through weak rather than strong ties. As close friends tend to move in the same circles, the information they receive overlaps considerably with what is already known. Acquaintances, in contrast, know people in other circles and thus receive more novel information. Granovetter (1973) argues that for diffusion across a network, weak ties are most valuable.

However, according to Krackhardt (1992), there are some problems with Granovetter's definition. Krackhardt (1992) contends that there are subjective criteria in the definition of the strength of a tie, such as emotional intensity and intimacy. He believes that strong 
ties are very important in cases of severe change and uncertainty.

The notion of structural holes theory (Burt, 1995) is related to some extent to the strength of weak ties theory. This theory draws on the fundamental idea that the homogeneity of information, new ideas and behaviour is generally higher within any group of people than between two groups of people (Burt, 2004). An individual who acts as a mediator between two or more closely connected groups of people could gain important comparative advantage. In particular, the position of acting as a bridge between distinct groups allows a person to transfer or gatekeep valuable information from one group to another. In addition, the individual can combine all the ideas received from different sources and come up with the most innovative idea based on all the information. At the same time, a broker also occupies a precarious position, as ties with disparate groups can be fragile and time-consuming to maintain.

\subsection{Open innovation}

According to Chandler (1977, 1990), important technology had been developed in the research sectors of large-scale European and American multimarket corporations by the middle of the twentieth century. The large-scale corporations of those days yielded a scale and economy of scope through vertical integration from the R\&D stage to distribution, and they established competitive advantage over small- and medium-sized enterprises or new-entry companies. However, Chesbrough (2003) argues that the vertical integration innovation model of Chandler $(1977,1990)$ had reached its limit, according to an empirical study of US industry, by the end of the 20th century. This is because, especially in high-tech companies, the liquidity of knowledge becomes greater if there is labour liquidity; venture funds helped to establish the new companies, which utilized such knowledge. Moreover, according to Langlois (2003), as proof of the shift from the Chandler model, the workforce was modularized and subdivided among companies as the need for vertical integration was lost. According to Grantstrand et al (1997), active learning processes, such as the acquisition of external technology and union of in-company technical capabilities, are needed in many cases to create competitiveness in a new field. Gulati (1998) gives an example in which a company strives for the absorption of knowledge through the exploitation of strategic alliances or complementary resources and further points out that such an alliance network approach is often observed in the bio industry, which especially needs advanced technology.

\subsection{External relationships in pharmaceutical companies}

Several studies have considered tangential relationships with an outside company. Roberts and Hauptman (1986) examined a new biophysics company that was often in contact with external companies in developing a product involving more advanced technology. Henderson and Cockburn (1994) investigated 120 or more research projects for ten top European and US pharmaceutical companies. They found that the percentage difference between the number of patents and amount of commercial production success in relation to research expenses was more than double for the successful company group compared to the ailing company group. The special features of the successful companies were as follows: 
$\checkmark$ They maintained a point of contact with a scientific field.

$\checkmark$ Resources were allocated to a wide range of medical treatment fields and the companies aimed for the most advantageous project mix.

$\checkmark \quad$ The tension and friction generated by the matrix organization of a function and a product were tackled positively.

Moreover, according to Koenig (1983), there is a correlation between the number of clinical trials or theses cited within a medicinal or pharmaceutical academic community and the productivity of an area of investigation. According to Gambardella (1992), a company that has sufficient relationships with institutional science also has an excellent research programme.

\subsection{Architectural competence in the medical industry}

Henderson and Cockburn (1994) classified R\&D capability into local capability and architectural competence and explored the relevance of organizational capability and the outcome of research on pharmaceutical products in terms of the development of drugs for circulatory organs in a European and US pharmaceutical company. Local capability is the fundamental individual capability and knowledge required for everyday problem solving. Architectural competence concerns the ability to use and unify local capabilities effectively and create new local capabilities that may be needed. Henderson and Cockburn (1994) developed and tested four hypotheses: the first two hypotheses concern the relationship between local capability and productivity in the development of new drugs and the second two address the relationship between architectural competence and productivity in the development of new drugs.

$\checkmark$ Productivity in the development of new drugs is an increasing function of a company's special professional knowledge in a specific field.

$\checkmark$ Productivity in the development of new drugs is an increasing function of local capability in a specific disease field.

$\checkmark$ A company with the capability to promote/sustain the flow of information, exceeding the boundaries of the company, has high productivity in the development of new drugs as long as other conditions are constant.

$\checkmark$ A company with the capability to promote/sustain the flow of information, exceeding the scientific principle and the boundaries between medical treatment fields, has high productivity in the development of new drugs as long as other conditions are constant.

Based on analysing the number of patents as an indication of development performance, Henderson and Cockburn (1994) found significant support for the first three hypotheses and demonstrated that local capability and architectural competence are related to productivity in the development of new drugs. Thus, the research claims that architectural competence, which is an organizational capability in connection with the integration and combination of information or knowledge from inside and outside an organization, is an important source of competitive advantage for a company.

Yeoh and Roth (1999) studied the source of sustainable competitive advantage for 20 
US pharmaceutical companies and performed an empirical study using the resourcebased view and organizational capability concepts. They showed that the cost of R\&D was directly related to the component capabilities of the company and that the R\&D expenses and the distribution of spending increased the company's integrative capabilities. Furthermore, an examination of the cause and effect relationship between local capability and the distribution of spending/integration capability showed variations between companies in the medical treatment field and that it yields new products at the global level. Pisano (2006) has undertaken various case studies on science innovation in biomedicine in recent years, reaching the conclusion that vertical integration is suitable for a company attempting the development of epoch-making pharmaceutical products scientifically.

\subsection{Intermediate organization}

According to Imai et al (1982), the rationale for coordination in a market is primarily based on price, whereas the rationale in an organization is authority or the order of relationships based on a hierarchy. From the viewpoint of mutuality between participants, entry or withdrawal from a market is straightforward and an organization is characterized by being fixed and continuous. The market mechanism and the principle of organization both have a relative advantage according to the trade environment and the characteristics of the goods being traded. As an interim mode, there is an intermediate organization, which is the network type, such as a keiretsu or strategic alliance. There are various types of networks that connect economic agents, reflecting the strength of the connection, duration and so on. An intermediate organization is considered an eclectic mode that addresses the weaknesses of the market or the business organization. According to Zenger and Hesterly (1997), the intermediate organizational mode of network type has increased in the information industry in recent years and the interpenetration of market and hierarchy has attracted attention in research.

\subsection{Platform leadership \& ecosystem}

Gawer and Cusumano (2013) define external or industry platforms as products, services or technologies developed by one or more firms, which serve as foundations upon which a larger number of firms can build further complementary innovations in the form of specific products, related services or component technologies. Iansiti and Levien (2004) note the role of the 'keystone firm', i.e. one that drives industrywide innovation for an evolving system of separately developed components. Industry platforms tend to facilitate and increase the degree of innovation in complementary products and services. The greater the innovation in such complementary aspects, the more value is created for the platform and its users via network effects, creating a cumulative advantage for existing platforms. As these grow, they become harder for rivals or new entrants to dislodge; the growing number of complements acts as a barrier to entry. Highlighting the complex trade-offs between 'open' and 'closed' innovations, Gawer and Cusumano (2008) suggest that while opening up interfaces will increase complementors' incentives to innovate, it is important to preserve some source of revenue and profit as proprietary.

According to lansiti and Levien (2004), within the business ecosystem three classes of 
company are described: keystone, dominator and niche player. Keystone and dominator strategies can be pursued by firms that occupy important hubs in their business networks. Niche strategies can be pursued by the much larger number of firms that make up the bulk of the ecosystem. They emphasize differentiation by focusing on unique capabilities and leveraging key assets provided by others. By being part of several competing networks, niche players can use the threat of leaving to keep keystones honest and to enjoy profitability.

\subsection{Cause uncertainty and result uncertainty}

A problem-solving model is formulized in five phases: (1) definition in question, (2) search for alternatives, (3) experiment (simulation), (4) assessment and (5) selection (Kuwajima, 1999). According to Simon (1988), generally, the central activity in problemsolving is (2) search for and (3) experiment (simulation) with alternatives. The cause uncertainty (width of a search) and result uncertainty (depth of a simulation) have been shown for every industry and product on the basis of a case study (Fujimoto \& Yasumoto, 2000). The product development trait of drug development and dosage form development can be classified according to two scales as compared with other products and industries. For example, in the beer industry, since there are many design parameters about taste and the combination is countless, a wide-ranging search is required. On the other hand, the test is simpler only when examined by a sensory test person. Additionally, in a new medicine development, in order to discover an effective compound, the researcher has to search thousands of alternatives. Also, as regards simulation, since it is difficult to predict the effect of a medicine and the toxicity of a compound, detailed trials, such as preclinical animal testing or a clinical human trial, are required (Kuwajima, 1999).

Furthermore, in a dosage form development, although the relevance of a compound and an additive agent, application of a drug delivery system, etc. need to be searched, a wide-ranging drug development search is not required. In addition, it is rare that the effect of a medicine and the toxicity of a new tablet cannot be forecast, and simulation is limited to a soundness test, a biological equivalence test, etc.

\subsection{Market needs ambiguity and product structure complexity}

Each industrial trait has been evaluated using the scales of the ambiguity of market needs, and the complexity of a product structure (Fujimoto \& Yasumoto, 2000). The ambiguity of market needs can specify a market and customer needs uniquely. A motor car is a typical example of a product with high ambiguity. Since the criteria for choosing a pharmaceutical product concern whether it is effective, ambiguity is low. The complexity of a product structure is related to the numerousness of the components that constitute a product, and the interdependence between each component. As a general trend, if the complexity of a product structure is high, the scale of a development organization will become large and its need for coordination between organizations will also increase. As a result, the need for internal integration will also increase. A typical example of a product with high product structure complexity is a motor car. Furthermore, the structural ingredients of pharmaceutical products are several, including a principal 
component and an additive agent. For this reason, there is not much engagement with $R \& D$ and the team is small. In such a small-scale team, since mutual coordination is easy, the need for internal integration is low (Kuwajima, 1999).

Furthermore, the user needs of a dosage form development are not only effect as with pharmaceutical products. The convenience that increases the adherence to medication, such as the ease of taking in by a patient and the ease of treatment by the physician, the nurse, the pharmacist and a patient's household, is evaluated. The ambiguity of a dosage form development is higher than the usual pharmaceutical products. In addition, the latest dosage form of pharmaceutical products has added various functions (orally disintegrating tablet, a sustained-release product, prefilled syringe, transdermal systems, etc.). Therefore, the complexity of the product structure is higher than that of the usual pharmaceutical products.

\section{Hypotheses and the verification methodology}

\subsection{Derivation of research hypotheses}

Based on the above-mentioned precedent research, some hypotheses can be derived about the interorganisational relation in the open innovation of a pharmaceutical product.

First, according to the simple and fundamental significance of an open innovation, if the number of external cooperation organizations increases, the opportunity for an innovation will increase and the research results will increase.

$\mathrm{H} 1$. If there are many external cooperation companies, innovation results will increase.

Or, the structure of cooperation may be more important than the amount of cooperation. One example is the so-called platform type of relationship structure. The abovementioned hypothesis 1 is the relationship to which other companies may be connected mutually directly. In the platform style, many companies are connected through a certain specific company, and there is little direct relation between other companies. It is thought that the opportunity for a valuable innovation increases if the positioning of its company is a node of two or more companies.

$\mathrm{H} 2$. If it is a position that serves as a node of several company groups, the results of an innovation will increase.

Or, the position of a niche style may also be effective. In cases where the niche company has an important scarce resource etc., an external company cannot but depend on the niche company. If the company of the niche style is directly connected with many central companies in cases where two or more central companies that form a platform exist, it will be thought that the results of an innovation increase.

H3. If the direct relation with several central companies is strong, the results of an innovation will increase.

On the other hand, the depth of cooperation may be more important than the amount of cooperation. For example, in cases where the information or technology that an external organization holds is implicit, absorption of external knowledge is difficult. In such a case, 
the concentration of the relationship with a specified enterprise is thought to strengthen the result of cooperation rather than increase the amount of external cooperation.

H4. If the relationship with an external company is narrow and deep, the results of an innovation will increase.

Conversely, the influence of the capability and management of a company may be greater than external cooperation. For example, in cases where technical integrated capability is more important, it is thought that the amount or the form of cooperation, etc. hardly influence the results of external cooperation. This is equivalent to the alternative hypothesis of the above-mentioned hypotheses.

H5. External cooperation does not influence the results of an innovation.

\section{2 Verification methodology}

As an analytical method, patents were extracted from the open Japanese patent database. The relationships between companies regarding innovation were surveyed by analysing the joint-application status of patents. When two or more companies applied for a patent jointly, it was assumed that there was cooperation regarding R\&D among these companies. To be specific, for each joint-application patent, the applicants' names and number of applications, etc. were extracted and an adjacency matrix was created. The adjacency matrix data were analysed using social network analysis. Finally, the relationship between each network indicator and each indicator regarding the results of R\&D was analysed. The methods and indicators of the social network analysis employed are addressed later. The top ten pharmaceutical companies in Japan were chosen for analysis: Takeda Pharmaceuticals, Otsuka Pharmaceutical, Astellas, Daiichi Sankyo, Eisai, Sumitomo Dainippon Pharma, Chugai, Tanabe Mitsubishi, Shionogi and Kyowa Hakko Kirin. In the case of mergers, all the names of the old company were transposed to that of the new company. The R\&D of pharmaceutical products is a lengthy process and there is usually a long period between a patent application and the sale of a product. Thus, in this research, data were extracted on patent applications from the year 2007 to the year 2016. In terms of firm performance, the financial data used were the business profit and R\&D expenses.

\subsection{Network analysis indicators}

This section addresses the method and indicators of social network analysis used for verification in the study. Social network analysis is the process of investigating social structures through the use of network and graph theories (Otte \& Rousseau, 2002). It characterizes networked structures in terms of nodes (individual actors, people or things within the network) and the ties, edges or links (relationships or interactions) that connect them. Examples of social structures commonly visualized through social network analysis include social media networks (Grandjean, 2016), message propagation in a social network service (Nasrinpour \& Friesen, 2016), friendship and acquaintance networks, collaboration graphs, kinship, disease transmission and sexual relationships (D'Andrea et al, 2010; Pinheiro, 2011). These networks are often visualized through sociograms, in which nodes are represented as points and ties are 
represented as lines. Network features can be at the level of individual nodes, dyads, triads, ties and/or edges, or the entire network. For example, node-level features can include network phenomena such as betweenness and centrality, or individual attributes such as age, sex or income (Hanneman \& Riddle, 2005).

Social network analysis software generates these features from raw network data formatted as an edge list, adjacency list or adjacency matrix (also called a sociomatrix), often combined with (individual-/node-level) attribute data (Hanneman \& Riddle, 2005). Although the majority of network analysis software uses a plain text ASCII data format, some software packages have the ability to use relational databases to import and/or store network features. Network analysis software generally consists of either packages based on graphical user interfaces (GUIs) or packages built for scripting/programming languages. In general, GUI packages are easier to learn, while scripting tools are more powerful and capable of extension. Widely used and well-documented GUI packages include NetMiner, UCINet, Pajek (freeware), GUESS, ORA, Cytoscape, Gephi, SocNetV (free software) and muxViz (open source). In this research, UCINet 6 for Windows was used.

With regard to the aforementioned hypotheses, of the various indicators employed in social network analysis, 'closeness centrality' was used as an indicator of the amount of external cooperation. In graph theory and network analysis, indicators of centrality identify the most important vertices within a graph. Applications include identifying the most influential person(s) in a social network, key infrastructure nodes in the Internet or urban networks and super-spreaders (of disease). Centrality concepts were first developed in social network analysis and many of the terms used to measure centrality reflect their sociological origin (Newman, 2010). The closeness centrality of a node is a measure of centrality in a network, calculated as the sum of the length of the shortest paths between the node and all other nodes in the graph. Thus the more central a node is, the closer it is to all other nodes in a connected graph.UCINet (https://sites.google.com/site/ucinetsoftware/home) calculates the farness and normalized closeness centrality and variants of each vertex and gives the overall network closeness centralization.

Next, 'brokerage' and 'betweenness' were used as indicators of the style of network platform. Brokerage is the number of pairs not directly connected. The idea of brokerage is that the ego is the 'go-between' for pairs of other actors. In an ego network, the ego is connected to every other actor. If these others are not connected directly to one another, the ego may be a 'broker' ego, intervening in the paths between others. UCINet (https://sites.google.com/site/ucinetsoftware/home) computes the number of times the ego lies on the shortest path between two alters, i.e. the number of pairs of alters that are not directly connected. Normalized brokerage is the brokerage divided by the number of pairs. This assesses the extent to which the ego's role is that of a broker. One can be in a brokering position a number of times, but this is a small percentage of the total possible connections in a network. UCINet (https://sites.google.com/site/ucinetsoftware/home) computes brokerage normalized by 
the number of brokerage opportunities, which is a function of ego network size.

Betweenness is an aspect of the larger concept of 'centrality'. Ego is 'between' two other actors if it lies on the shortest direct path from one to the other. The ego betweenness measure indexes the percentage of all geodesic paths from neighbour to neighbour that pass through the ego. UCINet (https://sites.google.com/site/ucinetsoftware/home) computes the sum of the proportion of times the ego lies on the shortest path between each pair of alters. For alters connected to each other, the contribution between the pair is zero. For alters connected to each other only through the ego, the contribution is 1 . For alters connected through the ego and one or more other alters, the contribution is $1 / k$, where $k$ is the number of nodes connecting that pair of alters. Normalized betweenness compares the actual betweenness of the ego and the maximum possible betweenness in the neighbourhood of the size and connectivity of the ego. The 'maximum' value for betweenness would be achieved in the case that the ego is at the centre of a 'star' network; that is, no neighbours communicate directly with one another and all communications between pairs of neighbours go through the ego. UCINet (https://sites.google.com/site/ucinetsoftware/home) computes ego betweenness normalized by a function of the number of nodes in the ego network. The notions of 'brokerage' and 'betweenness' are differing ways of indexing just how 'central' or 'powerful' the ego is within its own neighbourhood. This aspect of how an actor's embedding may provide strategic advantage has received a great deal of attention.

Next, 'eigenvector centrality' and 'Bonacich power centrality' were used as indicators of niche positioning. Eigenvector centrality is a measure of the influence of a node in a network (Bonacich, 1987). It assigns relative scores to all nodes in the network based on the concept that connections to high-scoring nodes contribute more to the score of the node in question than equal connections to low-scoring nodes. The eigenvector centrality thesis states that a node is important if it is linked to other important nodes. Eigenvector centrality is also a ranking measure (Leontief, 1941). UCINet (https://sites.google.com/site/ucinetsoftware/home) calculates the eigenvector of the largest positive eigenvalue as a measure of centrality. Bonacich power centrality (Bonacich, 1987) is closely related to eigenvector centrality. Power is a function of own centrality plus the centrality of others, weighted by the distance and number of walks between you and these others. Actors who are tied to very central actors should have higher prestige/centrality than those who are not. UCINet (https://sites.google.com/site/ucinetsoftware/home) computes Bonacich's power-based centrality measure for every vertex and gives an overall network centralization index for this centrality measure.

In addition, 'ego density' was used as an indicator of a strong narrow network. Density refers to the 'connections' between participants. Density is defined as the number of connections a participant has, divided by the total possible connections a participant could have. For example, if there are 20 people participating, each person could potentially connect to 19 other people. A density of $100 \%(19 / 19)$ is the greatest density in the system. A density of $5 \%$ indicates there is only 1 out of 19 possible connections 
(De Laat et al, 2007). UCINet (https://sites.google.com/site/ucinetsoftware/home) computes standard ego network measures for every actor in a network. This routine systematically constructs the ego network for every actor within the network and computes a collection of ego network measures. Both in and out networks can be considered separately or together.

\section{Result of the analysis}

\subsection{The extracted joint-application patent}

As mentioned above, the patent information for which major drug manufacturing companies applied in the past ten years was analysed. As a result, the extracted jointapplication patent was 5,753 items. Note that the number of patents is not the number of applications, but the number of registered patents. That is, the registered patent is a patent whose novelty was approved publicly.

Next, the classification was tried according to the type of product with the code of the patent classification about the extracted joint-application patent. Although there were a number of types of codes of patent classification, the International Patent Classification (IPC) was used. The IPC, established by the Strasbourg Agreement 1971, provides for a hierarchical system of language-independent symbols for the classification of patents and utility models according to the different areas of technology to which they pertain. The IPC is the most common currently and is applied widely. As a result of classifying all the extracted joint-application patents, they were mainly concentrated on the following classifications.

$\begin{array}{ll}\checkmark & \text { A61K: } 1,466 \text { items (25.5\%). } \\ \checkmark & \text { A61P: } 1,895 \text { items (32.9\%). } \\ \checkmark & \text { C07D: } 461 \text { items (8.0\%). } \\ \checkmark & \text { C12N: } 465 \text { items (8.1\%). }\end{array}$

According to the IPC (www.wipo.int), A61K is 'Preparations for Medical, Dental, and/or Toilet Purposes'. In addition, A61P is 'Specific Therapeutic Activity of Chemical Compounds or Medicinal Preparations'. A61K and A61P can be summarized as they are mainly patents regarding a dosage-form development. Meanwhile, C07D is 'Heterocyclic Compounds'. In addition, C12N is 'Biochemistry' (Beer; Spirits; Wine; Vinegar; Microbiology; Enzymology; Mutation or Genetic Engineering). C07D is mainly the conventional-style drug development of a low-molecular-weight style, and $\mathrm{C} 12 \mathrm{~N}$ is mainly summarized as it is the patent regarding a bio-drug development.

\subsection{Correlation analysis}

Next, the network analysis indicator of each company and the productivity of the research were calculated according to each above-mentioned classification. As a proxy variable of the productivity of a research, the ratio that divided the business profit by the research and development expenses was adopted. As already noted, the R\&D of pharmaceutical products is a lengthy process and there is usually a long period between a patent application and the sale of a product. Thus, in this research, the time lag was set to five years. Specifically, the financial data for the period 2013-2017 were derived 
from the Annual Securities Reports of each company.

Each correlation analysis result is shown in Table 1.

Note that if the statistic of Ego Density is small, it is shown that the relationship is narrow.

Table 1. Correlation analysis result with productivity of research

\begin{tabular}{|l|l|l|l|l|l|}
\hline $\begin{array}{l}\text { interorganisational } \\
\text { relation }\end{array}$ & indicator & biotech & $\begin{array}{l}\text { low } \\
\text { molecule }\end{array}$ & $\begin{array}{l}\text { dosage } \\
\text { form (P) }\end{array}$ & $\begin{array}{l}\text { dosage } \\
\text { form (K) }\end{array}$ \\
\hline Numerousness & $\begin{array}{l}\text { Closeness } \\
\left({ }^{*} 1\right)\end{array}$ & $.648^{*}$ & -.410 & -.072 & -.072 \\
\hline Platform & nBroker $\left.{ }^{*} 2\right)$ & -.180 & .256 & $.674^{*}$ & $.639^{*}$ \\
\cline { 2 - 6 } & $\begin{array}{l}\text { nEgoBetween } \\
\left({ }^{*} 3\right)\end{array}$ & -.097 & .256 & $.700^{*}$ & $.649^{*}$ \\
\hline \multirow{2}{*}{ Niche } & $\begin{array}{l}\text { Eigenvector } \\
\left({ }^{*} 4\right)\end{array}$ & $.715^{*}$ & .124 & .225 & .087 \\
\cline { 2 - 6 } & BonPwr $\left({ }^{*} 5\right)$ & $.719^{*}$ & .114 & .223 & .272 \\
\hline Depth & Ego Density & .180 & -.256 & $-.674^{*}$ & $-.639^{*}$ \\
\hline
\end{tabular}

(Note) (*1) closeness centrality, (*2) normalized brokerage, (*3) normalized ego betweenness, $\left({ }^{*} 4\right)$ eigenvector centrality, $\left({ }^{*} 5\right)$ Bonacich power centrality

(*: $5 \%$ of significance level)

\section{Discussion}

Each hypothesis is verified based on the above-mentioned results of the analysis. The optimal interorganisational relation was different even within the pharmaceutical industry according to the type as a result of the correlation analysis. In the enterprise activity regarding the open innovation in the past, and its empirical study, the results of an effect are not necessarily the same. Such a difference in the trait between products is assumed to be one of the reasons.

Among pharmaceuticals, in terms of biomedicine, hypothesis 1 and hypothesis 3 were supported and hypothesis 2, hypothesis 4 and hypothesis 5 were rejected. According to precedent research on interorganisational relations, an important issue is the integration between organisations that perform open innovation. In the pharmaceutical industry, the integration is the relationship with a pharmaceutical company, the physician, nurse and pharmacist of a hospital or bio-venture, contract research organization, etc. As a pattern of integration, a comparison of a broad shallow relationship and a narrow deep relationship can be considered. Also, according to precedent research, a search of alternatives (width of a search) and the ambiguity of market needs influence the selection of an integration pattern. If the value acquired through open innovation is the contingent encounter with technical information and market needs useful for a company, the width of a search by a broad shallow and ad hoc relationship is important.

Biomedicine is a comparatively new pharmaceutical area and various new research results are produced every day. In such an environment with active innovation, it is thought to become a source of innovation to absorb as much variety of external information as possible. On the other hand, in order to access a lot of information, a lot of managerial resources are necessary for search activities or cooperation activities. 
Although this may be possible in a company with rich managerial resources, if failure to cooperate continues, there is also a risk of lowering productivity. Therefore, it is thought that the strategy in which it cooperates, particularly with an important company that has taken a central position in the external network, is also effective. For a company that has taken the central position in a network it is highly likely that the research and development is excellent. A niche company that has complementary technology with such a central company can form an effective cooperative relationship, and is thought to raise the productivity of a research.

Only hypothesis 5, which is an alternative hypothesis, was supported regarding lowmolecular-weight pharmaceutical products, which are the conventional pharmaceuticals. According to precedent research, the important issues of management in an open innovation are the absorptive and architectural capabilities of an organization. Absorptive and architectural capability is considered to be related with the result uncertainty. If the result uncertainty is high, deep simulation in the R\&D of a product is needed. Therefore, it is difficult to connect the knowledge and information acquired from the outside to the knowledge and information of a company organization, and a longterm management process is required.

In the research and development of conventional products, in the absorption of external new technology, the experience accumulated in each company must be important. It is thought that experience cultivates integrated capability. A drug development is considered a typical example, and since the result uncertainty is high, a long-term management process is required. Rather than absorbing a lot of external new technology, the selection and concentration capability based on experience may raise the productivity.

Next, regarding a dosage form development, hypothesis 2 and hypothesis 4 were supported and hypothesis 1, hypothesis 3 and hypothesis 5 were rejected. Compared with the above-mentioned bio-drug development, the verification results were exactly opposite. When market needs are equivocal and the tacit knowledge factor is strong, external information is not understood easily. It is necessary to understand and absorb precious information by associating with the user of the product over many hours, and to make it unite carefully with the product development. In such a case, a deep long interorganisational relation is needed. The cause uncertainty of a dosage form development is not high compared with that of a drug development. In addition, since a solution proposal according to the various conditions of a therapy site or a patient is required, the ambiguity of the market needs in a dosage form development is high. $A$ deep relationship with a customer is searched for in a dosage form development.

In addition, if product structure complexity is high, it is not easy to manage a series of technologies and processes by integrating them in a company. Even if a company cooperates with an external organization, it is suitable to integrate an interorganisational relation. The motor industry is a typical example, and the interorganisational relation of a keiretsu system, which manages the inside and outside of an integrative organization, is effective. In a dosage form development, since the complexity of a product structure 
is larger than that of a drug development, integrative R\&D is required, understanding clearly the kind and quality of various materials in and outside the company, the various environments in a hospital, etc.

In addition, hypothesis 2 concerned innovation related to the style of the platform network. As a result of correlation analysis, it is thought that the interorganisational relation of a platform style raises the productivity in a dosage form development. As mentioned above, the network platform style is not simply related to network size or breadth. It is assumed that different industrial or technological groups are connected through a certain company. For example, in personal computing, Microsoft's OS came together by uniting hardware and software, thereby generating profitability. The same structure may apply to dosage form development. The R\&D capabilities that integrate equivocal market needs and various product technologies are thought to raise the productivity of the research in a dosage form development.

\section{Conclusion}

This research verified empirically the difference in interorganisational relationships in open innovation between different pharmaceutical products. In various previous studies on the development of new drugs, conclusions regarding the effects of open innovation have not necessarily been coherent. In this study, a suitable interorganisational relationship according to the difference in product characteristics, such as numerousness, platform, niche, and depth, became clear as a result of social network analysis. The implications of research findings may be useful for the decision-making of those who promote open innovation. The limitations of this research are the spans of the sample used for the survey. There is a possibility that the special conditions in the management environment of Japanese firms have influenced the search results. $A$ future study could generalize further by carrying out international comparison research, etc.

\section{Acknowledgement}

This work was supported by JSPS KAKENHI Grant Number 16K03916.

\section{References}

Bonacich, P. (1987) Power and centrality: A family of measures. American Journal of Sociology. 92 (5), 1170-1182. https://doi.org/10.1086/228631

Burt, R. S. (1995) Structural holes: The social structure of competition. Cambridge, MA, Harvard University Press.

Burt, R. S. (2004) Structural holes and good ideas. American Journal of Sociology. 110 (2), 349-399. https://doi.org/10.1086/421787

Chandler, A. D. (1977) The visible hand: The managerial revolution in American business. Boston, Harvard University Press.

Chandler, A. D. (1990) Scale and scope: The dynamics of industrial enterprise. Boston, Harvard University Press.

Chesbrough, H. W. (2003) Open innovation: The new imperative for creating and profiting from technology. Boston, Harvard Business School Press. 
D'Andrea, A., Ferri, F. \& Grifoni, P. (2010) An overview of methods for virtual social networks analysis. In: Abraham, A. (ed.) Computational social network analysis, London, Springer, pp. 3-25. https://doi.org/10.1007/978-1-84882-229-0_1

De Laat, M., Lally, V., Lipponen, L. \& Simons, R. J. (2007) Investigating patterns of interaction in networked learning and computer-supported collaborative learning: A role for social network analysis. International Journal of Computer-Supported Collaborative Learning. 2 (1), 87-103. https://doi.org/10.1007/s11412-007-9006-4

Fujimoto, T. \& Yasumoto, M. (2000) Effective product development pattern: A comparison across multiindustries. Tokyo, Yuhikaku.

Gambardella, A. (1992) Competitive advantage from in-house scientific research: The U.S. pharmaceutical industry in the 1980s. Research Policy. 21 (1), 1-17. https://doi.org/10.1016/00487333(92)90001-K

Gawer, A. \& Cusumano, M. A. (2008) How companies become platform leaders. MIT Sloan Management Review. 49 (2), 28-35.

Gawer, A. \& Cusumano, M. A. (2013) Industry platforms and ecosystem innovation. Journal of Production Innovation Management. 31 (3), 417-433. https://doi.org/10.1111/jpim.12105

Grandjean, M. (2016) A social network analysis of Twitter: Mapping the digital humanities community. Cogent Arts \& Humanities. 3 (1), 1171458. https://doi.org/10.1080/23311983.2016.1171458

Granovetter, M. (1973) The strength of weak ties. American Journal of Sociology. 78 (6), 1360-1380. https://doi.org/10.1086/225469

Granovetter, M. (2005) The impact of social structure on economic outcomes. Journal of Economic Perspectives. 19 (1), 33-50. https://doi.org/10.1257/0895330053147958

Grantstrand, O., Patel, P. \& Pavitt, K. (1997) Multi-technology corporations: Why they have 'distributed' rather than 'distinctive' core competencies. California Management Review, 39 (4), 8-25. https://doi.org/10.2307/41165908

Gulati, R. (1998) Alliances and networks. Strategic Management Journal, 19, 293-317. https://doi.org/10.1002/(SICI)1097-0266(199804)19:4<293::AID-SMJ982>3.0.CO;2-M

Hanneman, R. A. \& Riddle, M. (2005) Introduction to social network methods. Riverside, CA, University of California. [online] Available from: http://faculty.ucr.edu/ hanneman/ [Accessed 22 August 2017]

Henderson, R. \& Cockburn, I. (1994) Measuring competence? Exploring firm effects in pharmaceutical research. Strategic Management Journal. 15, 63-84. https://doi.org/10.1002/smj.4250150906

lansiti, M. \& Levien, R. (2004) The keystone advantage: What the new dynamics of business ecosystems mean for strategy, innovation, and sustainability. Boston, MA, Harvard University Press.

Imai, K., Itami, H. \& Koike, K. (1982) Economics of internal organization. Tokyo, Toyokeizai Shinposha.

Isada, F. \& Isada, Y. (2015) A network analysis of open innovation in drug discovery. Economy \& Business Journal. 9 (1), 94-110.

Koenig, M. (1983) A bibliometric analysis of pharmaceutical research. Research Policy. 12, 15-36. https://doi.org/10.1016/0048-7333(83)90024-0

Krackhardt, D. (1992) The strength of strong ties: The importance of philos in organizations. In: Nohria, N. \& Eccles, R. (eds.) Networks and organizations: Structure, form, and action. Boston, MA, Harvard Business School Press, pp. 216-239.

Kuwajima, K. (1999) Organizational capability in the research-and-development process of pharmaceutical products, Organizational Science, 33 (2), 88-104.

Langlois, R. N. (2003) The vanishing hand: The changing dynamics of industrial capitalism. Industrial and 
Corporate Change. 12 (2), 351-385. https://doi.org/10.1093/icc/12.2.351

Nasrinpour, H. R. \& Friesen, M. R. (2016) An agent-based model of message propagation in the Facebook electronic social network. arXiv preprint arXiv: 1611.07454.

Newman, M. E. J. (2010) Networks: An introduction. Oxford, Oxford University Press. https://doi.org/10.1093/acprof:oso/9780199206650.001.0001

Otte, E. \& Rousseau, R. (2002) Social network analysis: A powerful strategy, also for the information sciences. Journal of Information Science. 28 (6), 441-453. https://doi.org/10.1177/016555150202800601

Pinheiro, C. A. R. (2011) Social network analysis in telecommunications, Vol. 37. Hoboken, NJ, John Wiley \& Sons.

Pisano, G. P. (2006) Science business. Boston, Harvard Business School Press.

Roberts, E. \& Hauptman, O. (1986) The process of technology transfer to the new biomedical and pharmaceutical firm. Research Policy. 15, 167-185. https://doi.org/10.1016/0048-7333(86)90006-5

Simon, H. A (1988) The science of design: Creating the artificial. Design Issues. 4(1/2), 67-82. https://doi.org/10.2307/1511391

Wassily W. Leontief (1941) The structure of American economy, 1919-1929. Boston, Harvard University Press.

Yeoh, P. L. \& Roth, K. (1999) An empirical analysis of sustained advantage in the US pharmaceutical industry: Impact of firm resources and capabilities. Strategic Management Journal. 20 (7), 637-653. https://doi.org/10.1002/(SICl)1097-0266(199907)20:7<637::AID-SMJ42>3.0.CO;2-Z

Zenger, T. R. \& Hesterly, W. S. (1997) The disaggregation of corporations: Selective intervention, highpowered incentives, and molecular units. Organization Science, 8 (3), 209-222. https://doi.org/10.1287/orsc.8.3.209 